\title{
Intervenções do Cejusc sobre a violência doméstica contra a mulher na Comarca de União da Vitória - PR
}

\author{
CEJUSC assistance on domestic against women in the region \\ of União da Vitória - PR
}

Lucimara Dayane Amarantes*
Maria Luiza Milani**

\begin{abstract}
Resumo
Objetiva-se, com o presente artigo, explicar a violência doméstica como problema de múltiplas dimensões, que atinge as vítimas silenciosamente e não obedece a nenhuma regra rígida (nível social, econômico e cultural): tem tendência de impedir ou dificultar o desenvolvimento físico e mental das vítimas e agressores. Representa carga econômica em termos de produtividade, aumento do uso de serviços sociais e interferência na dignidade humana. Incide no desenvolvimento de uma nação, estado e região. Na comarca de União da Vitória, observou-se que a violência é mais expressiva que os dados manifestados. $O$ estudo foi produzido pela pesquisa bibliográfica e documental na instituição CEJUSC e o seu papel inovador no Poder Judiciário e nos setores de serviços que deveriam constituir a rede socioassistencial. Daí a importância da pesquisa que trouxe para discussão este tema e sustentou proposições, estratégias e intervenções mais definitivas, tanto para prevenção como para uma possível erradicação da violência doméstica.
\end{abstract}

Palavras-chave: Direitos humanos e sociais. CEJUSC. Violência Doméstica. Violência contra a Mulher. Rede Socioassistencial.

\begin{abstract}
We aim to explain domestic violence as a problem of multiple dimensions, which reaches the victims silently and does not conform to any rigid rule (social, economic and cultural level): tends to prevent or hinder physical development and the victims ' mental and aggressors. Represents economic burden in terms of productivity, increased use of social services and interference in human dignity. Focuses on the development of a nation, State and region. In the region of União da Vitória observed that violence is expressive of that data The study was produced by bibliographic and documentary research in the CEJUSC institution and its innovative role in the judiciary and in the service sectors that should constitute the socio-care network. Hence the importance of research to bring to the discussion this topic and support propositions, more definitive strategies and interventions for both prevention and for a possible eradication of domestic violence.
\end{abstract}

Keywords: Human and social rights. CEJUSC. Domestic Violence. Violence against Women. Give Social Assistence Network.

\footnotetext{
* Mestre em Desenvolvimento Regional, Assistente Social do Centro Judiciário de Solução de Conflitos e Cidadania da Comarca de União da Vitória (CEJUSC)

** Doutora em Serviço Social, Docente do Programa de Mestrado em Desenvolvimento Regional da Universidade do Contestado.
} 


\section{Introdução}

O tema deste artigo referiu-se às atribuições sociojurídicas do Centro Judiciário de Solução de Conflitos e Cidadania da Comarca de União da Vitória (CEJUSC), sobre o fenômeno da violência doméstica (BRASIL, 2005; ROCHA, 2010). Portanto, sob esse entendimento, a definição do tema deste trabalho adveio da experiência profissional da pesquisadora no CEJUSC, onde passa a vivenciar nos atendimentos diários as várias expressões da questão social ${ }^{1}$ e da violência doméstica, que permitiu compor um cenário de sua incidência na vida pessoal, familiar e social da demanda atendida, bem como se observa, nesta realidade vivenciada, o negligenciamento frente à violação dos direitos humanos, seja por parte dos governantes e mesmo pela própria sociedade.

A pesquisa induziu à reflexão acerca das contradições postas no cotidiano, em que se busca a garantia dos direitos dos cidadãos e também se depara com o conservadorismo latente de uma sociedade em sua composição machista e patriarcal. Consequentemente, tem-se um Estado desafiado a propor políticas públicas que atendam ao preconizado na Constituição Federal do Brasil de 1988, e que, garantam um mínimo protecional ao povo. Torna-se pungente repensar o sistema capitalista, estabelecido há decadas e que precariza cada vez mais a cidadania do povo.

Com relação às vulnerabilidades e às violências, bem como ao preconizado pelos Direitos Humanos e Direitos Sociais, o CEJUSC pelas suas atribuições sociojurídicas, torna-se um mediador entre a realidade das violências. Sua atuação preponderante é para o cumprimento das legislações, para o enfrentamento da violência e suas múltiplas formas e públicos (em especial dos segmentos vulneráveis da violência com incidência sobre as crianças e adolescentes, juventude, mulheres, idosos, entre outros). Frisa-se que o CEJUSC é advindo do modelo tradicional judiciário, herdado de modelo patriarcal, que possui o desafio de exercício pleno da cidadania.

\section{Materiais e métodos}

\footnotetext{
${ }^{1}$ Questão social é o conjunto das expressões que definem as desigualdades da sociedade. Nesse contexto, as expressões da "questão social" traduzem-se em uma potencialização do fetichismo da mercadoria com a banalização do humano, da satisfação das necessidades sociais e dos dilemas do trabalho. Soma-se o crescimento das desigualdades sociais, a regressão de direitos civis e sociais, a desregulamentação das relações de trabalho e a ascensão de políticas de ajuste estruturais preconizadas pelos países imperialistas. (IAMAMOTO, 2007).
} 
A pesquisa foi desenvolvida com base no fundamento teórico filosófico do materialismo dialético e para ser possível entender a garantia dos Direitos Humanos, pautada na construção social da história bem como na contradição existente na sociedade. Permeada por relações sociais dinâmicas, que se contrapõem, pela negação ou o não ao acesso aos direitos básicos fundamentais, contidos nos arcabouços legais previamente citados.

Ainda, sob essa concepção pela análise dialética, abordaram-se os variados fenômenos à realidade que permeia os Direitos Humanos e sua violação, no âmbito da violência e das violências domésticas. Para entendimento do processo das mudanças e dos conflitos sociais, investigou-se a realidade dinâmica que se encontra em mudança e transformação.

O diagnóstico exploratório desenvolvido no estudo foi sustentado pelas pesquisas bibliográfica e documental. Para a presente pesquisa, foram utilizados documentos produzidos no CEJUSC, que ainda não haviam passado por um tratamento analítico, como prontuários, relatórios, encaminhamentos. Foram coletados dados no local natural onde os fatos acontecem (município sede da Comarca de União da Vitória-PR). Foram identificadas, a priori, as seguintes estruturas e serviços integrantes da Rede Socioassistencial: Secretaria Municipal de Assistência Social (CRAS, CREAS), de Saúde, de Segurança Pública (Delegacia de Polícia Civil SDP/Regional e Delegacia da Mulher) e o Sistema Judiciário composto por: Vara da Infância e Adolescência, da Família, 1aㅡ e 2a Varas Criminais e o CEJUSC (GROSSI; TAVARES; OLIVEIRA, 2008).

\section{Centro de Resolução de conflitos e Cidadania (CEJUSC)}

O CEJUSC é constituido pela Resolução no 125, de 29/11/2010, que dispõe sobre a Política Judiciária Nacional de tratamento adequado aos conflitos de interesses no âmbito do Poder Judiciário e objetiva possibilitar a atuação para o acesso mais rápido da população à justiça, de forma ampla, por meio da orientação jurídica, utilizando-se de métodos consensuais de solução de conflitos (CONSELHO NACIONAL DE JUSTIÇA, 2010). O CEJUSC possibilita pôr em pauta o desenvolvimento de novas formas de convivência, que explora o diálago profundo entre as pessoas, como uma ferramenta de transformação das mesmas para mediar os conflitos de forma saudável, proporcionando uma comunicação não violenta, de maneira que as pessoas expressem suas necessidades assertivamente, edificando respostas em torno da cooperação na convivência solidária. 
Frente ao fenômeno da violência e, em especial da violência doméstica, o CEJUSC almeja oferecer atendimento aos usuários deste serviço do Sistema Judiciário, de modo adequado, para que as situações de violência não venham a agravar-se ou até mesmo, perpetuarem-se. A atuação do CEJUSC visa qualidade do serviço prestado para a garantia de acesso a uma ordem jurídica justa, na construção de uma cultura de paz² social. Ou seja, é uma intervenção institucional judiciária com a finalidade de ampliar a aproximação e democratização de justiça e cidadania, mediante à intervenção educativa, para os direitos e cultura de pacificação social.

O atendimento proposto no programa de enfrentamento à Violência Doméstica do CEJUSC, tem início no acolhimento e entrevista realizada pelo serviço social, surgindo inúmeras questões que são vislumbradas na medida em que ocorrem estes atendimentos. Portanto, esta pesquisadora, propõe a partir da experiência profissional, o estudo aprofundado e exploração dos dados obtidos nos atendimentos, bem como o contato e entrevista com gestores da Rede Socioassistencial, a serem realizados no município sede da Comarca de União da Vitória-PR, analisando-os, para que possam subsidiar um programa de atendimento com maior eficácia e efetividade ao público envolvido.

O direito de acesso à Justiça, previsto no art. 5o, XXXV, da Constituição Federal de 1988 (BRASIL, 1988), além da vertente formal perante os órgãos judiciários, alude acesso à ordem jurídica justa. Portanto, cabe ao Poder Judiciário estabelecer política pública de tratamento adequado aos problemas jurídicos e aos conflitos de interesses, que tramitam em larga e crescente escala na sociedade, de forma a organizar, em âmbito nacional, não somente os serviços prestados nos processos judiciais, como também os que possam sê-lo mediante outros mecanismos de solução de conflitos. Com destaque aos métodos consensuais, como a mediação e a conciliação, que são instrumentos efetivos de pacificação social, solução e prevenção de litígios e a sua apropriada disciplina nos programas já implementados no país, têm reduzido a excessiva judicialização dos conflitos de interesses, a quantidade de recursos e de execução de sentenças.

\footnotetext{
${ }^{2}$ O movimento, a Cultura de Paz iniciou-se oficialmente pela UNESCO (Organização das Nações Unidas para a Educação, a Ciência e a Cultura) em 1999 e empenha-se em prevenir situações que possam ameaçar a paz e a segurança - como o desrespeito aos direitos humanos, discriminação e intolerância, exclusão social, pobreza extrema e degradação ambiental - utilizando com principais ferramentas a conscientização, a educação e a prevenção, ou seja, a cultura de Paz está intrinsecamente relacionada à prevenção e à resolução não violenta de conflitos e fundamenta-se nos princípios de tolerância, solidariedade, respeito à vida, aos direitos individuais e ao pluralismo (INFOJOVEM, 2017).
} 
O Conselho Nacional de Justiça (CNJ) tem papel fundamental na organização e na promoção de ações de incentivo à autocomposição de litígios e à pacificação social, pois ao implantar o Movimento pela Conciliação, em agosto de 2006, teve por objetivo transformar a cultura da litigiosidade e promover a busca de soluções para os conflitos, mediante à construção de acordos. O Movimento promoveu encontros e debates sobre o tema, em 2006, e lançou a Semana Nacional da Conciliação, evento anual que abrange todos os tribunais do País e, em 2010, com o crescimento das demandas internas sobre o tema, foi editada a Resolução no 125, que dispôs sobre a Política Judiciária de Tratamento Adequado dos Conflitos de Interesse no Âmbito do Poder Judiciário, com ênfase à responsabilidade social na atuação do Poder Judiciário, auxiliando na preservação e restauração de vínculos entre pessoas, melhorando seu desempenho social (CONSELHO NACIONAL DE JUSTIÇA, 2010).

A pacificação social decorrente dessa política é notória, na medida em que, conciliadas, as partes deixam de gerar novas demandas e ganham confiança no sistema de justiça. Além da Resolução 125/2010, o Conselho também publicou a Recomendação no 50/2014 (CONSELHO NACIONAL DE JUSTIÇA, 2014a) para estimular e apoiar os tribunais na adoção das técnicas consensuais de resolução de conflitos e a Resolução no 198/2014 (CONSELHO NACIONAL DE JUSTIÇA, 2014b), que dispõe sobre o Planejamento e a Gestão Estratégica no âmbito do Poder Judiciário para o sexênio 2015-2020, o que ressalta a importância da efetividade na prestação jurisdicional e aponta como cenário desejado: uma justiça mais acessível, desjudicialização, descongestionamento do Poder Judiciário. Na perspectiva dos processos internos, as metas estão relacionadas à celeridade e produtividade na prestação jurisdicional e à adoção de soluções adequadas no tratamento de conflitos, reforçando a importância da política pública.

No enfrentamento à violência doméstica, devido a falta de infraestrutura adequada na Rede Socioassistencial, o Sistema Judiciário torna-se indispensável ao bom funcionamento do sistema nacional e também, internacional de proteção, em que existem diversos instrumentos úteis ao desenvolvimento e proteção dos direitos humanos das mulheres, em especial com os novos âmbitos e olhares das recentes políticas judiciárias, que permitem maior rapidez e um olhar mais integral à pessoa.

As obrigações assumidas pelo Brasil, por meio de tratados internacionais de proteção à mulher, nas quais já se somam 67 anos da Declaração Universal dos Direitos Humanos (1948), reforçadas pela Constituição Federal em 1988, resultando em compromissos 
assumidos com o Pacto Nacional pelo Enfrentamento à Violência contra a Mulher (BRASIL, 2011), das deliberações tomadas no III Encontro Nacional da Comissão Permanente de Combate a Violência Doméstica (COPEVID) e do previsto na Lei Maria da Penha no 11340/06 (BRASIL, 2006), fornecem as bases para a sustentação ao enfrentamento dos casos de violência doméstica.

\section{Violência doméstica e contra a mulher na Comarca de União da Vitória - PR}

No recorte direitos humanos, inserem-se também os direitos civis e os direitos sociais e jurídicos (Art. 5o da CFB de 1988 e seus 78 incisos que abordam os direitos fundamentais). Dessa forma, a garantia de tais direitos ((Art. 60 da CFB de 1988) está diretamente vinculada às intervenções dos governantes e do Estado, na proposição de políticas públicas (STROMQUIST, 1996), bem como em sua implementação e execução para atender às necessidades apresentadas pela população.

Sendo assim, a violência nas suas diversas formas, acaba por demonstrar a inoperância governamental em garantir certos direitos aos cidadãos. A violência atinge níveis alarmantes, incidindo em diversos segmentos sociais, demonstrando um processo de desconstitucionalização de direitos, aceita pelos governos e pela sociedade civil, reproduzindo a exclusão e a desigualdade, resultando em retrocesso e desconsideração ao direito fundamental da cidadania.

Sobre as suas manifestações, a violência denominada simbólica (BOURDIEU, 1989) atenta contra as crenças, a cultura e a própria identidade dos indivíduos, que se tornam vítimas. Por conseguinte, a violência engloba tudo aquilo que não é desejado pelo outro, e que lhe é imposto pela força concreta ou simbólica, por exemplo: necessidade, fome, miséria, que ferem a dignidade humana, incidindo na impossibilidade de uma vida com o mínimo necessário para a sobrevivência.

Em suma, a violência resulta do uso abusivo ou injusto do poder, assim como do uso da força que resulta em ferimentos, sofrimento, tortura ou morte. O conceito de violência é dinâmico e reproduz transgressão das normas e dos valores socialmente instituídos em cada momento histórico (OMS, 2002)

A violência e as manifestações da violência promovem um custo social (BARCELAR, 2013) e este interfere nos processos de desenvolvimento em particular sobre as dimensões humano-sociais. Também este custo repercute negativamente no desenvolvimento, tanto 
local como regional, uma vez que marca o lugar e a região, demanda mais intervenções e deixa a sociedade em situação de vulnerabilidade. Destaca-se que este custo social da violência tem magnitude e intensidade que envolvem desde a vida pessoal das vítimas e agressores, assim como as implicações sociais e individuais dela resultantes.

Em vista disso, o custo social traduz-se em um dispêndio socioeconômico. É imensurável no nível emocional e psicológico, pois leva a perda das relações sociais, produz isolamento e pânico. Repercute na questão econômica, com perdas financeiras significativas, que incidem diretamente na vida social dos indivíduos que sofrem com a violência e na sociedade de uma forma geral. Sendo que, em virtude da violência instituída existe uma ruptura das redes sociais e interpessoais das partes envolvidas, resultando no isolamento social, o absenteísmo escolar, nas dificuldades em promoções, dificuldades em arranjar emprego, desemprego, entre outras consequências gravíssimas.

Faz-se mister, mencionar também que a redução das desigualdades regionais no Brasil é demarcada na Constituição de 1988, posteriormente, surge a Política Nacional de Desenvolvimento Regional, pelo Decreto 6.047 de 22 de fevereiro de 2007 (BRASIL, 2007), que objetiva "a redução das desigualdades de nível de vida entre as regiões brasileiras e a promoção da equidade no acesso às oportunidades de desenvolvimento e deve nortear os programas e ações federais no Território Nacional". Posteriormente, a Portaria no 77/2013, instituiu o Regulamento da Etapa nacional da I Conferência Nacional de Desenvolvimento Regional (CNDR) e a Portaria no 80/2018, que estabelece as Rotas de Integração Nacional como estratégia de desenvolvimento regional e inclusão produtiva do Ministério da Integração Nacional. Mesmo com o reconhecimento da gravidade e impacto que a violência ocasiona, analisou-se que os documentos legais, os quais deveriam convergir para o desenvolvimento, tais como os referidos acima, não contemplam questões relativas ao aspecto humano e social.

Custo social (LISBOA; BARROS; CEREJO, 2015) este que, por falar de violência doméstica e contra as mulheres, não apenas aborda as consequências ao nível físico, psicológico ou outro patamar. Quando se observa o fenômeno mais efetivamente, percebese que a violência exercida tem vários tipos de custos; os que comprometem a vítima em nível individual, como em relação aos que estão mais próximos (familiares, filhos); custos que incidem diretamente sobre as pessoas envolvidas e que são pagos por toda a sociedade, nomeadamente por meio dos impostos, como as casas, abrigo, polícia, magistrados, técnicos 
de apoio social; custos que têm uma expressão econômica e difíceis de quantificar, como os psicológicos, sociais e culturais; custos visíveis em curto prazo, normalmente associados aos atos de violência; outros custos que se prolongam ao longo da vida, como o estresse póstraumático, ou mesmo que incidem nas gerações futuras, por meio dos seus filhos.

Há outros custos que, devido a sua natureza, só são observados com instrumentos qualitativos, onde os aspectos que se relacionam com as dimensões emocionais e afetivas cujas implicações podem ter expressão na ação pessoal cotidiana ou em ações futuras. Comumente, costuma designar-se por avaliação quantitativa dos custos o que diz respeito somente a uma das suas dimensões, a econômica.

Alguns desses custos podem ser objetos de cálculo macroeconômico, como aqueles que se expressam por faltas ao trabalho, perdas salariais, devido a não progressão na carreira e aos despedimentos, tempo e dinheiro gastos com divórcios, separações conjugais, médicos, medicamentos e meios suplementares de diagnóstico, idas aos hospitais e a centros de saúde, internamentos, incapacidades e outros prejuízos econômicos resultantes do insucesso escolar das vítimas e dos filhos.

Igualmente são de assinalar outros custos relativos aos gastos orçamentais de organizações públicas e privadas e de instituições do Estado com a violência; estes particularmente dependentes da produção de estatísticas oficiais, muitas vezes insuficientes, portanto, difíceis de avaliar, deflagrando como a violência coloca em risco a saúde física e psicológica. Ou seja, a vida das vítimas, pois ela resulta em mutilações, queimaduras, lesões que oneram a saúde pública (OMS, 2005), muitas vezes com tratamentos muito caros e dolorosos, que, em muitas ocasiões, são somente paliativos, pois não há como reverter os danos sofridos pelas vítimas. A violência produz quadros psiquiátricos graves, com tratamentos prolongados e períodos de crises intensas, como quadros de depressão, com risco de suicídio, síndrome do pânico, entre outros.

\section{Violência doméstica na Comarca de União da Vitória - PR}

Pensar em desenvolvimento, inicia-se por localizar as condições locais e regionais de progressão, consequentemente direcionando à região delimitada ao estudo do presente trabalho. São necessárias referências de desenvolução referentes como a população como saúde e escolaridade, o Índice de Desenvolvimento Humano Municipal (IDHM), bem como a incidência de casos atendidos em um semestre no CEJUSC: 
Na comarca de União da Vitória-PR, havia aproximadamente 200 casos a serem estudados no período que se propõe, (maio de 2015 a dezembro de 2017, somente no CEJUSC), sem mencionar outros dados e instituições que atendem situações de violência doméstica ou subnotificações desta demanda.

Quadro 2: Dados da Comarca de UVA/PR CEJUSC - 2016 e 2017

\begin{tabular}{|c|c|c|}
\hline MUNICíPIOS & CASOS ATENDIDOS EM 2016 & CASOS ATENDIDOS EM 2017 \\
\hline União da Vitória & 38 & 01 \\
\hline Bituruna & 03 & 07 \\
\hline Cruz Machado & 00 & 04 \\
\hline General Carneiro & 03 & 05 \\
\hline Paula Freitas & 03 & 03 \\
\hline Porto Vitória & 02 & 00 \\
\hline Porto União & 02 & 79 casos (03 masculinos e76 femininos) \\
\hline Total & 61 casos (02 masculinos e 59 \\
\end{tabular}

Fonte: Dados da Pesquisa (2018)

O mapeamento dos casos atendidos de violência aconteceu por um trâmite legal, determinado por documentos, como o Pacto e Plano Nacional para e Enfrentamento da Violência contra a Mulher e também, o Plano Nacional de Enfrentamento da Violência Sexual contra Crianças e Adolescentes, nos quais se propõem protocolos de atendimento nas áreas envolvidas no atendimento como a Saúde, Assistência Social, Segurança Pública e Sistema Judiciário; para o que, geralmente as portas de entrada são Prontos Atendimentos Emergenciais (PAE) ou Unidades Básicas de Saúde (UBS).

Sobre essa realidade e esse trâmite, tem-se conhecimento de que, em União da Vitória-PR, existe uma subnotificação, com grande déficit de notificações perante à demanda que acaba chegando ao CEJUSC. Assim sendo, o número de registros de casos de violências contemplado, não expressa a realidade fidedigna. Deduziu-se, por sua vez, que a violência é muita mais expressiva que os dados estão manifestando, visto a observação de casos advindos da Delegacia da Mulher e Varas Criminais para o CEJUSC; logo, a pesquisa contribuiu para demonstrar a extensão da violência no território pesquisado.

A violência doméstica traz a tendência de impedir ou dificultar um bom desenvolvimento físico e mental destas mulheres que sofreram violência, pois grande parte delas apresenta uma baixa autoestima, afetando sua saúde e qualidade de vida. Estas agressões, muitas vezes, nem chegam ao conhecimento das autoridades responsáveis e provocam um sofrimento indescritível às vítimas, em sua grande maioria completamente 
desorientadas e desamparadas. Além disso, muitas vezes, os serviços ineficientes, morosos ou sobrecarregados não ofertam o necessário para a superação de uma condição assim descrita e de vulnerabilidade diante da violência sofrida.

Como já destacado, a violência representa uma grande carga econômica para a sociedade, em termos de produtividade perdida e aumento no uso de serviços sociais, incidindo diretamente no encadeamento de uma nação, estado e região, e ainda em suas peculiaridades territoriais. O território, como espaço aqui apreendido, conforme designa Milton Santos (1978), é entendido, em sua materialidade, com objetivações e subjetivações, ou seja, o "espaço" é uma instância social, assim como a política, a economia e a cultura. Milton Santos (1978), procurou criar, produzir e desenvolver um método de análise geográfico, tendo como base a dialética. Ou seja, demonstrar a dinamicidade que incide na vida social e, consequentemente, nos territórios.

Em União da Vitória e região, observa-se que a violência é muita mais expressiva que os dados estão manifestando, por isso propôs-se inserir a perspectiva de gênero nas discussões sobre o Desenvolvimento Regional. A Região de União da Vitória está conformada em uma dinâmica bem conservadora e de ordem patriarcal, que define o poder do gênero masculino branco e heterossexual, conforme denota Saffioti e Almeida (1987). Onde se esconde uma ideologia sexista, que omite desvantagem masculina, transformando-a em desvantagem na inferioridade social da mulher, diante da ideologia de gênero, pois, desde os primórdios, o masculino prevaleceu sobre o feminino. Saffioti e Almeida (1987), descreve o sexismo não como uma ideologia, mas como estrutura de poder cuja distribuição é muito desigual em detrimento das mulheres, que são sempre "amputadas" no desdobramento e no uso da razão, bem como no exercício do poder. Ou seja, a sociedade requer mulheres dóceis, comportadas, cordatas e apaziguadoras, ao contrário dos homens, que são estimulados à disputa do poder, com condutas perigosas, que denotem força e coragem.

No enfrentamento à violência doméstica, devido à falta de infraestrutura adequada na Rede Socioassistencial, o Sistema Judiciário torna-se indispensável ao bom funcionamento do sistema nacional e também internacional de proteção. Para isso, existem diversos instrumentos que são úteis à evolução e proteção dos direitos humanos e fornecem as bases para a sustentação ao enfrentamento dos casos de violência doméstica. A saber, a Justiça vai subsidiando a agilidade da perspectiva de garantir os direitos humanos, de forma a municiar 
a sociedade acerca do cumprimento das leis e para que o enfrentamento da violência seja efetivo, saiam do papel e tomem formas concretas.

Torna-se, dessarte, imprescindível o trato à questão da violência, pois como disputa do poder e manutenção da hegemonia política e da cultura patriarcal (RONDON FILHO; FREIRE, 2009) e das violências, caracterizadas em suas diversas expressões, nos mais variados segmentos, ou se faz a justiça em relação aos Direitos Humanos ou a problemática da violência, em suas múltiplas expressões, terá uma incidência cada vez maior, prevalecendo o mito da impunidade e da violência como natural.

Entende-se tal prerrogativa, tendo em vista que o objeto da pesquisa é delineado no cenário da violência doméstica, que representa oneração econômica, social e ética para a sociedade, em múltiplos segmentos e esferas públicas.

Nesta perspectiva, o recorte de estudo proposto explicou como acontece a intervenção do CEJUSC, parte integrante de uma rede socioassistencial regional, a qual presta o atendimento necessário aos processos de violência doméstica, tendo como base as orientações e determinações dos direitos humanos, como pressuposto da dignidade humana e, por conseguinte, essas intervenções, tanto do ente institucional do CEJUSC como da rede, preveem repercussão no desenvolvimento humano e social na região da Comarca de União da Vitória-PR.

\section{Resultados e discussões}

Para iniciar a análise dos resultados e discussões pertinentes, definiu-se antes o Fluxograma da Comarca e do CEJUSC, como estavam configurados. Em relação à Comarca, efetua-se o atendimento de pessoas encaminhadas para o Programa de Enfrentamento à Violência Doméstica dos seis municípios que compõem esta Comarca. Porém, destaca-se que se realizam as entrevistas para os demandados dos municípios menores e os possíveis encaminhamentos, sendo impossível a frequência das mulheres entrevistadas no Grupo Primeiro Passo, devido às questões de deslocamento que se torna inviável, pois geralmente, estão atreladas aos seguintes fatores: seja por conta de família, cuidar de filhos pequenos, por trabalho ou questão econômica, falta de recurso para subsídio do transporte. Geralmente, são encaminhados os casos para acompanhamento de Rede Socioassistencial local. 
Em relação à Região de União da Vitória/PR, observou-se, por meio da prática profissional, uma média de 70 casos atendidos semestralmente no CEJUSC, no Programa de Enfrentamento à Violência Doméstica.

Figura 1: Fluxograma da Comarca de União da Vitória-PR

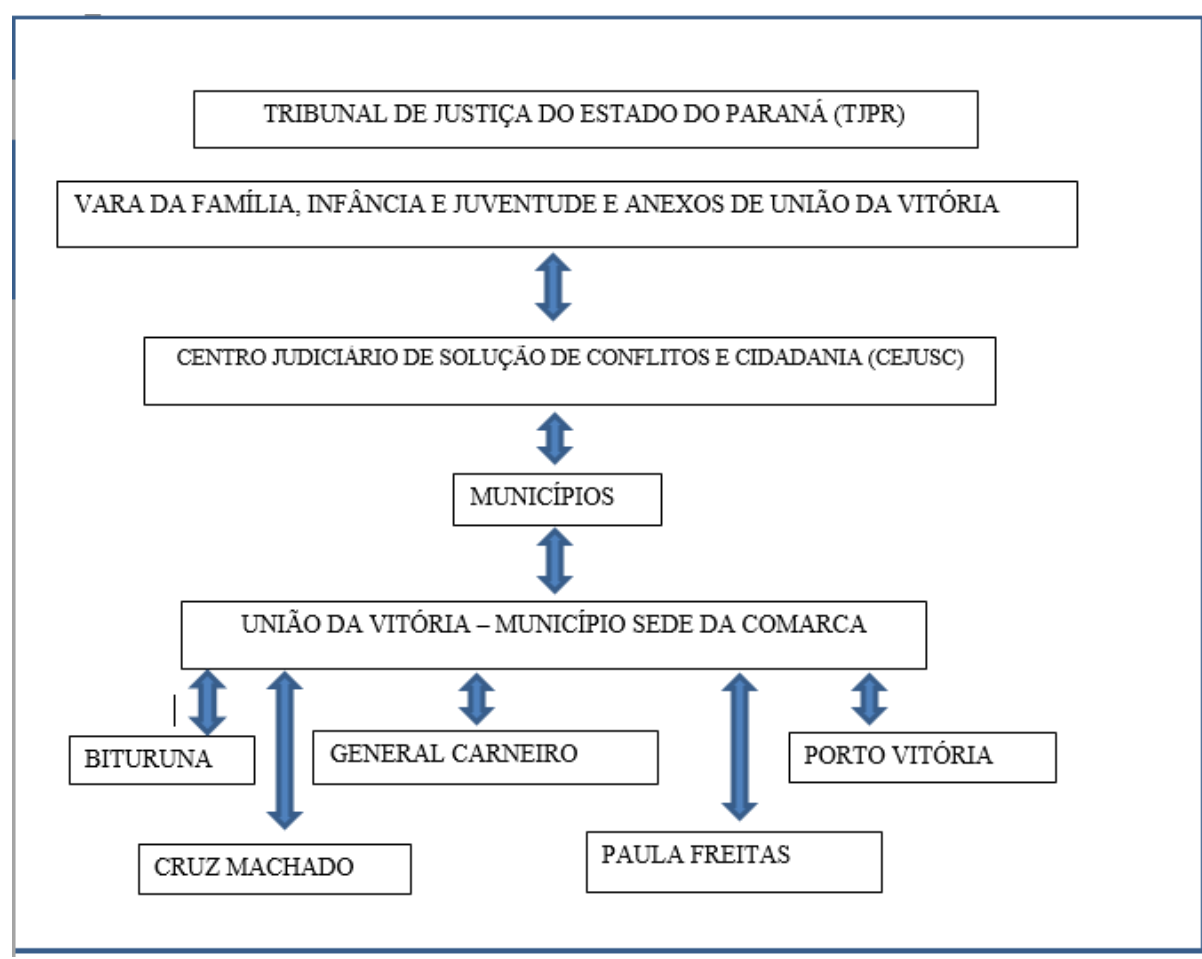

Fontes: Dados da pesquisa (2018)

Como se definiu, a priori, o estudo da rede socioassistencial do município sede da Comarca, seguem-se elencados os serviços diretamente relacionados ao atendimento de pessoas que sofrem violência doméstica, conforme demonstra fluxograma abaixo. 
Figura 2: Fluxograma do Centro Judiciário de Solução de Conflitos e Cidadania (CEJUSC)

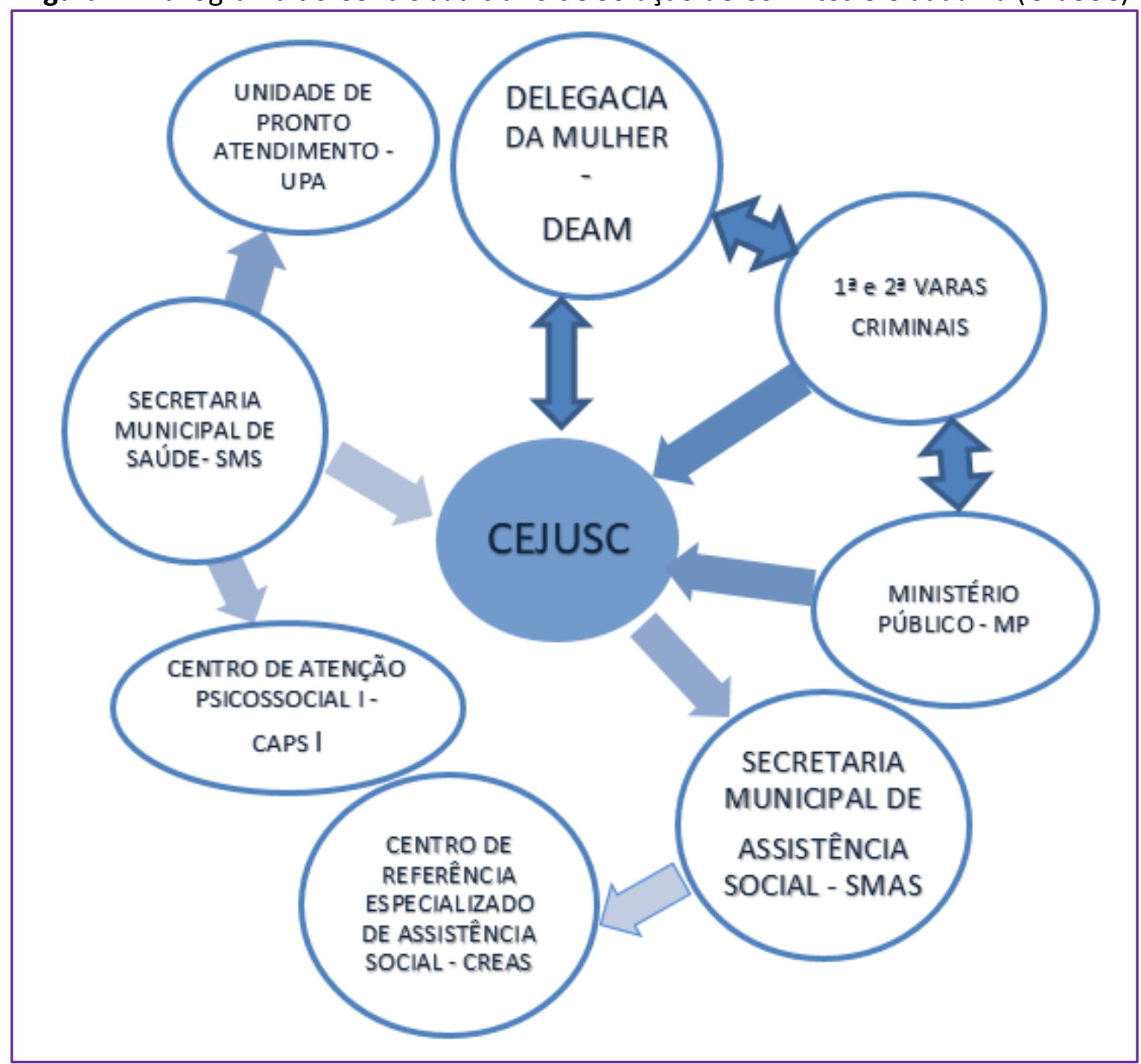

Fonte: Dados da pesquisa (2018)

\section{Atribuições dos serviços da Rede Socioassistencial}

A rede socioassistencial foi organizada no momento da pesquisa por instituições e entidades, as quais têm as seguintes atribuições no tocante ao atendimento às mulheres vítimas de violência:

- CEJUSC - Instância mediadora entre os serviços da Rede, atende aos casos encaminhados por outros serviços como Delegacia da mulher, Serviço de Saúde e de Assistência Social, Varas Criminais e também, buscas espontâneas de pessoas que buscam o serviço para orientações.

- Delegacia da Mulher - Órgão competente por assegurar o combate à violência contra as mulheres, e tem como objetivo específico o fortalecimento e a efetiva 
implementação de atendimento policial especializado para mulheres, por intermédio das atividades de investigação, prevenção e repressão dos delitos praticados contra as vítimas; bem como auxiliar as agredidas, seus autores e familiares a encontrarem o caminho da não violência, mediante trabalho preventivo, educativo e curativo efetuado pelos setores jurídico e psicossocial. Portanto, à autoridade policial compete: prender o agressor em flagrante sempre que houver qualquer das formas de violência doméstica contra a mulher; registrar o boletim de ocorrência e instaurar o inquérito policial (composto pelos depoimentos da vítima, do agressor, das testemunhas e de provas documentais e periciais); bem como remeter o inquérito policial ao Ministério Público; e ainda requerer ao juiz, em 48 horas, que sejam concedidas diversas medidas protetivas de urgência para a mulher em situação de violência e solicitar ao juiz a decretação da prisão preventiva (CONSELHO NACIONAL DE JUSTIÇA, 2018).

- 1a e 2a Varas Criminais - A Lei Maria da Penha estabelece que todo o caso de violência doméstica e intrafamiliar é crime e deve ser apurado por meio de inquérito policial e ser remetido ao Ministério Público, pois esses crimes serão julgados nos Juizados Especializados de Violência Doméstica contra a Mulher, criados a partir dessa legislação, ou nas cidades em que ainda não existem, nas Varas Criminais. A lei também tipifica as situações de violência doméstica, proíbe a aplicação de penas pecuniárias aos agressores, amplia a pena de 1 para até 3 anos de prisão e determina o encaminhamento das mulheres em situação de violência, assim como de seus dependentes, a programas e serviços de proteção e de assistência social. Em referência ao processo judicial: 0 juiz poderá conceder, no prazo de 48 horas, medidas protetivas de urgência (suspensão do porte de armas do agressor, afastamento do agressor do lar, distanciamento da vítima, dentre outras). Dependendo da situação, o juiz do juizado de violência doméstica e familiar contra a mulher terá competência para apreciar o crime e os casos que envolverem questões de família (pensão, separação, guarda de filhos etc.); e o papel do Ministério Público será apresentar denúncia ao juiz e poderá propor penas de 3 meses a 3 anos de detenção, cabendo ao juiz a decisão e a sentença final.

- Secretaria Municipal de Saúde - Política social de atendimento para a população no que tange à saúde pública, em conjunto com demais setores do munícipio.

- Centro de atenção Psicossocial-CAPS I - Referência de atendimento em Saúde Mental, onde se atendem muitos casos em comum, devido ao grande índice de uso abusivo de álcool e drogas na região. 
- Secretaria Municipal de Assistência Social - Política social de atendimento para a população no que tange a serviços de atenção básica da Política Nacional de Assistência Social, como o serviço do CRAS, onde se desenvolve o Programa de Atenção integral a Família - PAIF.

- Centro de Referência Especializado em Assistência Social-CREAS - Serviço de atenção especializada da PNAS, onde se atendem os casos de pessoas que tiveram seus direitos violados.

Ressalta-se que estes serviços estão na linha de frente dos atendimentos realizados para o enfrentamento da violência doméstica, estabelecendo um fluxo contínuo de atendimentos em rede, porém, também existem setores importantes onde são desenvolvidas ações preventivas ou até mesmo, decorrem os encaminhamentos e/ou contribuições das áreas da habitação, da educação municipal e estadual, das IES de União da Vitória e Porto União, dos Coletivos Feministas locais e regionais, entre outros.

A partir de maio 2015, iniciou-se uma parceria do CEJUSC com as Instituições de Ensino UNIGUAÇU e UNESPAR na realização dos Encontros de Gênero, Feminismo e Políticas Públicas, idealizados pela professora Mestre Dulceli L. Tonet Estacheski, do Curso de História, doutoranda da UFSC, na temática Gênero, Políticas Públicas e Violência, que contou com a parceria de outros cursos da IES-UNESPAR e do Curso de Serviço Social da UNIGUAÇU, bem como com a participação dos Coletivos Feministas Mais que Amélias e Insurgência Feminista, ambos da região de União da Vitória-PR. Na primeira edição do Encontro, aconteceu a 1a Sessão do Fórum de Políticas Públicas para Mulheres, um espaço de discussão democrática, sendo de extrema relevância para a proposição de ações a este segmento, ainda em construção na Região, em 2015, 2016 e 2017.

O procedimento realizado para a coleta de dados da pesquisa de campo, foi a entrevista semiestruturada aplicada individualmente para gestores e gestoras da Rede Socioassistencial de União da Vitória-PR. Assim como para os sujeitos do gênero feminino participantes do grupo Primeiro Passo com encontros regulares quinzenais, as terças-feiras, no CEJUSC da Comarca de União da Vitória-PR, coordenado pelo Serviço Social com apoio da Psicologia desta unidade.

A entrevista aconteceu no local de trabalho e de atendimento dos sujeitos em abordagem, realizada pela pesquisadora e teve duração de aproximadamente 15 a 20 minutos em local reservado, para que o sujeito da pesquisa respondesse a entrevista dentro da Instituição, mas de forma que a integralidade de suas respostas não fosse afetada. 
No cotidiano das intervenções do CEJUSC, como ente jurídico entre as pessoas que sofreram violências domésticas, é promovido tanto a intermediação, como ato que serve para ligar dois agentes, bem como a mediação, a qual significa as moventes passagens entre as partes (complexos) em face de uma totalidade (complexo que se constitui na soma de outros complexos menos abrangentes). Daí decorre que a não apreensão das mediações que compõem a ossatura da realidade, e redunda em análises e conclusões descabidas em face da convivência, e mais ainda, em ações descoladas às reais necessidades e possibilidades historicamente determinadas (PONTES, 1995).

Pôde-se identificar número reduzido de casos que demandaram à medida protetiva, como também o não prosseguimento com o acompanhamento adequado de programas que possibilitem entender e superar a violência doméstica.

Tanto no âmbito da mediação, como da intermediação, os entes institucionais devem intervir convergentemente para o exercício da cidadania e o trabalho desenvolvido em conjunto, com maior interface e intersetorialidade entre os diversos serviços afins, (convergência no enfrentamento da violência foi mencionado por $25 \%$ dos entrevistados como uma das barreiras e desafios perante o fenômeno da violência doméstica).

Para garantir a consolidação das políticas públicas e sua implantação, a Política Nacional para e Enfrentamento da Violência contra a Mulher prevê quatro áreas estruturantes: a primeira, organizada para a implantação da Lei Maria da Penha, já desenvolvida por meio do setor de segurança pública e justiça e envolvendo a área da saúde. A segunda área contemplaria a Proteção dos Direitos Sexuais e Reprodutivos e Enfrentamento da Feminização da AIDS. À terceira área caberia também à segurança pública e à justiça efetivarem o Combate à Exploração Sexual de Meninas e Adolescentes e ao Tráfico de Mulheres. Para dar conta da quarta área, caberia à assistência social a Promoção dos Direitos Humanos das Mulheres em Situação de Prisão. Enquanto o Pacto Nacional para o Enfrentamento da Violência contra a Mulher (BRASIL, 2011, p. 6), organizado em eixos os quais convergem com as áreas estruturantes da Política Nacional, materializando--se no conceito de Rede, que diz respeito ao conjunto de ações e serviços de diferentes setores, em especial, da assistência social, da justiça, da segurança pública e da saúde, que visam a ampliação e a melhoria da qualidade do atendimento, a identificação e aos encaminhamentos adequados das mulheres em situação de violência e a integralidade e humanização ao atendimento. 
A rede de atendimento à mulher em situação de violência está dividida em quatro principais setores/áreas (saúde, justiça, segurança pública e assistência social) e é composta por duas principais categorias de serviços: I) Serviços não-especializados de atendimento à mulher - que, em geral, constituem a porta de entrada da mulher na rede (a saber, hospitais gerais, serviços de atenção básica, programa saúde da família, delegacias comuns, polícia militar, polícia federal, Centros de Referência de Assistência Social/CRAS, Ministério Público, defensorias públicas, posto avançado de atendimento à migrante) e II) Serviços especializados de atendimento à mulher - aqueles que atendem exclusivamente as mulheres em situação de violência.

\section{CEJUSC - violência doméstica}

Com essa base, tornou-se pertinente questionar o avanço no número de casos de violência doméstica atendidos pelo CEJUSC, se está avançando no desenvolvimento social e humano de uma população regional? Mesmo que a pesquisa tenha recortado uma representatividade de setores e atores que atuam diretamente com o enfrentamento da violência doméstica, na comarca de União da Vitória, observou-se contradições postas e expostas; o caráter contraditório persiste quanto ao desconhecimento ou a fragmentação deste, relativos com algumas questões fundamentais à convivência pacífica na sociedade. Neste enfoque, a articulação dos setores sociais e instituições em uma rede compromissada com o fenômeno da violência doméstica vem se desenvolvendo fragilizada.

Este é definido como sendo um complexo de dimensões (econômicas, sociais, políticas, culturais, ambientais) produzidas dialética e historicamente, cujos desdobramentos têm se mostrado tendencialmente vinculados a uma construção de setores e de classes, nas quais se situam os sujeitos históricos.

Uma sociedade com as características locais e regionais como na qual está inserida a comarca de União da Vitória, reflete os processos históricos em várias direções, ou seja, do passado mais remoto da colonização brasileira com seu modo específico de explorar as riquezas, bem como da ocupação do espaço geográfico, dando o caráter conservador que é representado no modo de produzir e reproduzir os modos das relações sociais e naturais.

Quando se retrocede na composição e atual configuração da realidade social da região onde se localiza União da Vitória, vê-se que comporta setores que segmentaram o modo de produzir, de viver e de estabelecer relações sociais. 


\section{Conclusão}

Neste estudo, demonstrou-se a intervenção do CEJUSC, que objetiva oferecer atendimento, com qualidade do serviço prestado, para o acesso a uma ordem jurídica justa, eficiente e com objetivo da cultura de paz social, aos usuários deste serviço do Sistema Judiciário. Portanto, é uma intervenção institucional judiciária, com a finalidade de ampliar o acesso e democratização de justiça e cidadania, mediante a intervenção educativa, para os direitos e a cultura de pacificação social. Uma inovação no Sistema Judicário, que visa romper com o conservadorismo posto e agilizar os atendimentos aos cidadãos.

Sendo assim, o CEJUSC, abrangendo o território da Comarca de União da Vitória, possui um papel de mediador entre os serviços da rede socioassistencial que trabalham interdisciplinarmente no enfrentamento à violência doméstica. Isso posto, possibilita-se que muitos casos venham a encontrar uma solução mais ágil e pacificadora, desta forma evitando o agravamento de alguns casos de violência doméstica.

No entanto, observou-se que esta organização inicial de toda a rede de serviço, ainda não comporta todos os atendimentos necessários, nem contempla os recursos humanos adequados e capacitados para tal empenho na realização de um trabalho tão complexo e tão delicado. Ainda que todos os trabalhos procurem desenvolver suas funções e competências da melhor maneira que podem, ainda faltam mecanismos e equipamentos essenciais para desenvolver um trabalho mais efetivo em relação ao enfrentamento da violência doméstica, como o andamento da Política para Mulheres, a qual se encontra em fase de planejamento no município sede. Não aconteceu ainda nenhuma conferência ou se tem uma instância própria, como a Secretaria da Mulher. Refletindo que a Política Nacional já data há mais de dez anos. Portanto, o espaço de controle social encontra-se em construção, referindo os Eventos realizados pelo Fórum de políticas para Mulheres Vale do Iguaçu, que até o momento configuraram uma expressão inicial desta discussão.

Trabalha-se no enfrentamento à violência, deparando-se diariamente com uma realidade hostil, que não deixa um tempo para as pessoas resolveram seus conflitos pessoais e familiares. As situações vão agravando-se, até mesmo por ordem de uma cultura social reproduzida, onde as coisas são desta forma, não devem ser questionadas ou haver mudanças, no que está definido há tanto tempo. 
O que incide diretamente no desenvolvimento regional, tendo como consequência direta o adoecimento ou até perda de vidas produtivas, pautando-se aqui numa visão econômica; por outro lado, esfaceladora de famílias e comunidades, em uma visão humanosocial. Apresentando um alto custo social e econômico a ser pago por toda a sociedade.

Denota-se, em relação à violência doméstica, um comportamento da sociedade como um todo, que repercute na vida cotidiana de uma forma geral, retratando o individualismo que sobrepõe ao coletivo e à responsabilidade privada dos cidadãos, que se sobrepõe ao público e ao dever do Estado, onde o mundo financeiro vai cada vez mais se impondo sobre o cotidiano da vida dos indivíduos. Falar, pesquisar e produzir conhecimento sobre o desenvolvimento regional, bem como propor ações que sejam efetivas, é rever a atual política de Desenvolvimento Regional, sair do âmbito somente econômico e buscar um olhar maior e integral da realidade, englobando a discussão e o enfrentamento humano/social, econômico e político da violência doméstica em todas as suas dimensões necessárias, bem como a sensibilização da igualdade de gênero, da cultura da paz e da erradicação da violência e todas as suas formas de expressões. O que ocorrerá por meio de uma educação social ampla e democrática. Dessa maneira, atuar-se-á para ter a repercussão de um desenvolvimento regional sustentável, igualitário, que transforme realidades, que nos aproxime realmente do preconizado no artigo 43 da Constituição Federal de 1988.

\section{Referências}

BARCELAR, Tânia. As mulheres no momento atual do desenvolvimento econômico e social: desafios de um projeto de país com igualdade entre mulheres e homens e sustentável. $\ln : 3^{\mathrm{a}}$ CONFERÊNCIA NACIONAL DE POLÍTICAS PARA AS MULHERES: AUTONOMIA E IGUALDADE PARA AS MULHERES, 3., 2013, Brasília. Anais [...]. Brasília: Secretaria Nacional de Políticas para as Mulheres, 2013.

BOURDIEU, Pierre. O poder simbólico. Rio de Janeiro: Editora Bertrand Brasil, 1989.

BRASIL. [Constituição (1988)]. Constituição da República Federativa do Brasil de 1988. Brasília: Presidência da República, 1988. Disponível em:

http://www.planalto.gov.br/ccivil_03/constituicao/constituicao.htm. Acesso em: 12 out. 2017.

BRASIL. Decreto no 6.047, de 22 de fevereiro de 2007. Institui a Política Nacional de Desenvolvimento Regional - PNDR e dá outras providências. Brasília: Presidência da república, 2007. Disponível em: http://www.planalto.gov.br/ccivil_03/_Ato20072010/2007/Decreto/D6047.htm. Acesso em: 5 dez. 2017. 
BRASIL. Lei no 11.340, de 7 de agosto de 2006. Cria mecanismos para coibir a violência doméstica e familiar contra a mulher, nos termos do $\S 8^{\circ}$ do art. 226 da Constituição Federal, da Convenção sobre a Eliminação de Todas as Formas de Discriminação contra as Mulheres e da Convenção Interamericana para Prevenir, Punir e Erradicar a Violência contra a Mulher; dispõe sobre a criação dos Juizados de Violência Doméstica e Familiar contra a Mulher; altera o Código de Processo Penal, o Código Penal e a Lei de Execução Penal; e dá outras providências. Brasília: Presidência da República, 2006. Disponível em: http://www.planalto.gov.br/ccivil_03/_ato2004-2006/2006/lei/l11340.htm. Acesso em: 15 dez. 2017.

BRASIL. Presidência da República. Enfrentando a violência contra a mulher. Brasília: Secretaria Especial de Políticas para as Mulheres, 2005.

BRASIL. Secretaria Especial de Políticas para as Mulheres. Pacto nacional de enfrentamento à violência contra as mulheres. Brasília: SPM, 2011.

CONSELHO NACIONAL DE JUSTIÇA. Resolução no 125 de 29 de novembro de 2010. Dispõe sobre a Política Judiciária Nacional de tratamento adequado dos conflitos de interesses no âmbito do Poder Judiciário e dá outras providências. Brasília: CNJ,2010.

CONSELHO NACIONAL DE JUSTIÇA. Recomendação no 50, de 8 de maio de 2014. Recomenda aos Tribunais de Justiça, Tribunais Regionais do Trabalho e Tribunais Regionais Federais realização de estudos e de ações tendentes a dar continuidade ao Movimento Permanente pela Conciliação. Brasília: CNJ, 2014a. Disponível em: https://www.cnj.jus.br/wpcontent/uploads/2011/02/recomendacao_50_08052014_09052014145015.pdf. Acesso em: 15 dez. 2017.

CONSELHO NACIONAL DE JUSTIÇA. Resolução $n^{\circ} 198$, de 1 de julho de 2014. Dispõe sobre o Planejamento e a Gestão Estratégica no âmbito do Poder Judiciário e dá outras providências. Brasília: CNJ, 2014b.

CONSELHO NACIONAL DE JUSTIÇA. Manual de Rotinas e Estruturação dos Juizados de Violência Doméstica e Familiar contra a Mulher. 2 Ed Revisada e atualizada. Brasília. CNJ. Setembro de 2018. Disponível em https://www.cnj.jus.br.

DECLARAÇÃO UNIVERSAL DOS DIREITOS HUMANOS. Assembleia Geral das Nações Unidas em Paris. 10 dez. 1948. Disponível em: www.dudh.org.br/wp-content/uploads/2014/12/dudh.pdf. Acesso em: 26 jun. 2017.

GROSSI, Patrícia Krieger; TAVARES, Fabrício André; OLIVEIRA, Simone Barros. A rede de proteção à mulher em situação de violência doméstica: avanços e desafios. Athenea Digital, Porto Alegre, v. 14, p. 267-280, 2008. Disponível em: https://pdfs.semanticscholar.org/6b44/2c24e6297331a69676507 fab3cce8882f1c7.pdf. Acesso em: 7 dez. 2012.

IAMAMOTO, Marilda Vilela. Serviço social em tempo de capital fetiche. São Paulo: Cortez, 2007. 
INFOJOVEM. Cultura da paz. Disponível em: https://www.infojovem.org.br/infopedia/descubra-e-aprenda/cultura-de-paz/. Acesso em: 12 dez. 2017.

LISBOA, Manuel; PITA-BARROS, Pedro; CEREJO, Sara Dalila. Custos sociais e econômicos da violência exercida contra as mulheres em Portugal: dinâmicas e processos socioculturais. In: LISBOA, Manuel; PITA-BARROS, Pedro; CEREJO, Sara Dalila. Mundos sociais: saberes e práticas. Lisboa: Associação Portuguesa de Sociologia, 2008. Disponível em: http://www.aps.pt/vicongresso/pdfs/60.pdf. Acesso em: 14 dez. 2015.

OMS - ORGANIZAÇÃO MUNDIAL DA SAÚDE. Informe mundial sobre a violência e a saúde. Washington, DC: OMS, 2002.

OMS - ORGANIZAÇÃO MUNDIAL DE SAÚDE. Estudo multipaís da OMS sobre a saúde da mulher e da violência doméstica contra a mulher. Suíça: OMS; 2005.

PONTES, Reinaldo Nobre. Mediação e serviço social: um estudo preliminar sobre a categoria teórica e sua apropriação pelo serviço social. São Paulo: Cortez; Belém, PA: Universidade da Amazônia, 1995.

ROCHA, Carmen Lucia Antunes. O direito a uma vida sem violência. In: LIMA, Faustoi; SANTOS, Claudete (coord.). Violência doméstica: vulnerabilidades e desafios na intervenção criminal e multidisciplinar. 2. ed. Rio de Janeiro: Lumen Juris, 2010.

RONDON FILHO, Edson Benedito; FREIRE, Francisco Xavier. Monopólio legítimo da força como processo civilizador: Weber e Elias em perspectiva. In: SIMPÓSIO INTERNACIONAL PROCESSO CIVILIZADOR, 12., Recife, 2009. Anais [...]. Recife, 2009. Disponível em:

http://nacoesunidas.org/violencia-contra-a-mulher-e-a-violacao-de-direitos-humanos-maistolerada-no-mundo-afirma-onu /?utm_source= facebook. com\&utm medium=social\&utm_campaign=Postcron.com._Acesso em: $7 \mathrm{dez} .2015$.

SAFFIOTI, Heleieth I. B.; ALMEIDA, Suely de Souza. Violência de gênero: poder e impotência. Rio de Janeiro: Revinter, 1987.

SANTOS, Milton. Por uma geografia nova. São Paulo: Hucitec, 1978.

STROMQUIST, Nelly. Políticas públicas de estado e equidade de gênero: perspectivas comparativas. Revista Brasileira de Educação, Rio de Janeiro, n. 1, jan./abr. 1996.

UNIÃO DA VITÓRIA. Vara da Infância e Juventude, Família e Anexos - Comarca de União da Vitória - Centro Judiciário de Solução de Conflitos e Cidadania (CEJUSC) . Resolução no 125, de 29 de novembro de 2010 (com as alterações da Emenda no 1, de 31 de janeiro de 2013). Acesso em: setembro de 2017. 